Produto \& Produção, vol. 16 n.4, p. 84-103,dez. 2015

RECEBIDO EM 21/11/2012. ACEITO EM 20/07/2015.

\author{
Eva Bessa Soares \\ Universidade Federal de Ouro Preto - UFOP \\ eva@deenp.ufop.br
}

Wagner Ragi Curi Filho

Universidade Federal de Ouro Preto - UFOP

wagner@deenp.ufop.br

\title{
Olhares sobre a prevenção dos acidentes de trabalho
}

\section{RESUMO}

Este artigo traz, a partir da revisão de abordagens de autores nacionais e internacionais, alguns pontos de vista sobre a questão do acidente de trabalho e sua prevenção. No espaço desse artigo, não se pretendeu esgotar esta complexa discussão, apenas apresentar pontos de vista sobre a temática. São relatadas as duas principais abordagens sobre o acidente: a tradicional e a contemporânea, além de dados relacionados aos processos educativos para prevenção de acidentes. Na conclusão, são apontados aspectos concernentes à prevenção do acidente de trabalho. Embora ela seja possível, ainda há muito a ser feito em questões teóricas e práticas para se afirmar que a atuação de uma empresa está pautada em prevenção de danos à saúde do trabalhador.

Palavras-chave: Prevenção; Comportamento seguro.

\begin{abstract}
This article presents, from a review of approaches to national and international authors, some views on the issue of occupational accidents and their prevention. Within this article, did not intend to discuss this complex, only to submit views on the subject. Statistics were two main a approaches to the accident: the traditional and contemporary, as well as data related to educational processes for accident prevention. In conclusion, several aspects concerning the prevention of accidents at work. Although it is possible, much remains to be done in theoretical and practical issues to be said that performance of a company is guided by preventing damage to workers' health.
\end{abstract}

Keywords: Prevention; Safe behavior.

\section{Introducão}

Estudos relacionados a acidentes de trabalho, à saúde e segurança do trabalhador no Brasil são muitos, sendo que nessa introdução será feito um breve comentário a respeito o número 32 (115) da Revista Brasileira de Saúde Ocupacional do ano de 2007 dedicado a uma excelente coletânea sobre o referido tema. 
$\mathrm{Na}$ apresentação dessa revista, Filho (2007) aponta aspectos que tem influenciado o crescimento dos estudos nessa área, a saber: a) as universidades brasileiras vem buscando aprimoramento da qualidade de sua produção científica. Esse aspecto tem ampliado a difusão de novas formas de pensar a segurança, o risco e a prevenção, além de promover o diálogo entre pesquisadores e interessados de diferentes áreas relacionadas a esses estudos. Tem também aumentado o desenvolvimento de estudos centrados em múltiplos aspectos dos acidentes do trabalho; b) crescimento na oferta de serviços de saúde do trabalhador; c) as transformações pelas quais o Brasil vem passando refletindo-as nas áreas de saúde e segurança do trabalho na esfera governamental e nos centros de pesquisa. Dessa forma, tem aumentado o número de sistemas para os quais a ocorrência de acidentes, desastres ambientais e outros eventos de grandes impactos e incômodos sociais e políticos tem se tornado preocupação estratégica.

No cenário descrito no parágrafo anterior destacam-se incentivos para os questionamentos sobre os limites da abordagem tradicional de acidentes que os explica como eventos decorrentes de comportamentos faltosos dos trabalhadores. Há uma busca de novos caminhos pautados em explicações centradas em enfoque sistêmico, sociotécnico ou psico-organizacional. Esse último caminho tende a aproximar os sistemas preocupados em compreender e prevenir acidentes de trabalho e as universidades brasileiras. Dessa forma, esse artigo pretende realizar uma breve revisão da literatura sobre a segurança do trabalhador, apontando os limites da abordagem tradicional e as possibilidades de ampliação da análise da ocorrência dos acidentes trazidas pela abordagem contemporânea.

\section{Abordagens sobre acidentes de trabalho}

Nesse tópico não se pretende fazer um relatório exaustivo, ou mesmo, esgotar a discussão acerca das abordagens sobre os acidentes de trabalho, apenas apresentar os princípios e limites das abordagens consideradas: tradicional e contemporânea em segurança do trabalho. Para tal, foi feita uma breve revisão de literatura, apresentando alguns dos autores nacionais e internacionais representantes dessas duas abordagens.

$\mathrm{Na}$ chamada abordagem ou paradigma tradicional (CATTINO, 2002; LLORY, 1999; DWYER, 2000) o acidente é considerado culpa do trabalhador, evento simples, unicausal, produto do azar ou do acaso, fatalidade, evento negativo, produto do erro humano decorrente do desrespeito às normas ou de decisões conscientes dos operadores. Sob as considerações desse paradigma, há a dicotomia ato inseguro - ato seguro. A preocupação é identificar e punir os culpados pelo ocorrido para que não cometam novamente o referido ato.

Uma das principais limitações da abordagem tradicional sobre os acidentes de trabalho é a sua consideração sobre a exposição do ser humano apenas a perigos concretos e visíveis que causam danos ao corpo (GARRIGOU et al., 2007) como os acidentes com cortes, quedas, torções nos pés, pancadas na cabeça, etc. São ignorados os riscos não visíveis como a sobrecarga gerada pelo tratamento de informações, excesso de responsabilidades, ritmo intenso de trabalho, formas de supervisão, remuneração inadequada, horas extras abusivas dentre outras. A representação do ser humano e do perigo tem uma limitação por considerar somente os agravos à saúde relativos à integridade física, tanto as doenças profissionais como os acidentes. As dimensões cognitivas inerentes a todo trabalho são subestimadas ou até mesmo ignoradas. Como exemplos são citadas as situações de sobrecarga cognitiva na busca e tratamento das informações ou de pressão temporal que implicam o risco de produzir diversas disfunções referentes à eficácia e/ou confiabilidade do sistema, além de possíveis danos à saúde física e psíquica. $\mathrm{Na}$ prática, de muitas empresas brasileiras tem predominado essa abordagem que prioriza culpar o acidentado. Em algumas situações, o trabalhador acidentado falece e a empresa, sem ter a quem punir, não adota medidas para prevenir novas ocorrências de acidentes.

A Teoria dos dominós Heinrich (1932) aponta o acidente como causado por alguma coisa anterior ao acidente em si. Para esse autor, onde há pessoas, o acidente poderá ocorrer, sendo que ele nunca ocorre por acaso. Sua causa pode ser explicada porque o homem não é devidamente preparado, comete muitos tipos de atos inseguros ou existem condições inseguras que comprometem sua segurança. Essa teoria é, atualmente, bastante difundida na literatura e seu modelo está na legislação brasileira (Normas Regulamentadoras 4, 5, 18, NBR 14280). Sob as considerações de Heinrich (1932), 
o acidente é o resultado de uma sequência linear de eventos que podem ser comparados com cinco pedras enfileiradas de um jogo de dominós em pé. Essas pedras podem ser assim denominadas: 1) ambiente social (questões relacionadas à personalidade do trabalhador), 2) causa pessoal (falha humana durante a realização do trabalho), 3) ato inseguro - condição insegura (causa mecânica), 4) acidente e 5) lesão.

$\mathrm{O}$ ambiente social do trabalhador envolve dois fatores principais: hereditariedade e influência social. A personalidade é influenciada por questões herdadas de seus antepassados e também daquelas do meio onde ele está inserido. Dessa forma, o comportamento de uma pessoa em situação de trabalho, por exemplo, pode sofrer influências também das pessoas com as quais ele convive: excesso de confiança, irresponsabilidade, teimosia em não acatar determinados procedimentos de segurança.

A causa pessoal de acidentes está relacionada ao conjunto de conhecimentos e habilidades que cada um possui para realizar uma tarefa. Sua ausência ou deficiência pode dificultar o desempenho e predispor à ocorrência de acidentes. A causa mecânica diz respeito às falhas materiais existentes no ambiente de trabalho que podem expor as pessoas a acidentes como, por exemplo: equipamentos sem proteção, manutenção inadequada, má concepção no layout.

$\mathrm{O}$ ato inseguro é considerado a violação de um procedimento de segurança que poderá ocasionar acidentes. Quando um ou mais dos fatores supracitados se manifestam, ocorre o acidente podendo ou não provocar lesão ao trabalhador.

Já a visão contemporânea dos acidentes tira o foco do trabalhador enquanto culpado pelo acidente e engloba o sistema no qual ele está inserido. A partir dessa visão sistêmica, é considerado que, em um processo produtivo, há variações humana e também na produção requerendo regulações constantes por parte do trabalhador. $\mathrm{O}$ trabalho é visto como um conjunto de aspectos materiais, organizacionais e subjetivos. Nesse contexto, o trabalhador está sempre fazendo prevenção a partir de modificações em seus comportamentos cotidianos para enfrentar os desafios das situações laborais. Nessa perspectiva, a compreensão dos acidentes tem a ver com o entendimento dos motivos pelos quais os eventos causadores do acidente não foram detectados e evitados não apenas pelo trabalhador, mas pelos demais profissionais envolvidos no projeto da situação de trabalho na qual ele está envolvido.

O acidente deixa de ser considerado apenas como erro humano, isto é, centrado na demandas cognitivas, perceptuais e fisiológicas dos trabalhadores para ser considerado um evento inserido em um sistema (processo produtivo). Suas causas não são claras, mas podem originar de inadequações mais profundas do sistema: problemas de concepção, de comunicação nas equipes, deficiências gerenciais e outros. Nessa visão, o erro humano não é considerado falta de atenção, de interesse, desmotivação e negligência do trabalhador. Busca-se entender o comportamento dele e o sentido de suas ações no momento do acidente. Possivelmente, a partir dessa nova visão, seja possível pensar e atuar na prevenção de acidentes, enquanto que, na visão tradicional, busca-se apenas identificar o culpado para puni-lo. Dessa forma, não há contribuição para promoção de saúde e segurança dos trabalhadores e também não ocorre adoção de medidas para evitar novas ocorrências de acidentes.

Para adotar medidas efetivas em prevenção de acidentes, faz-se necessária a realização de análises no contexto de trabalho. Jorgensen (1998) traz contribuições significativas nesse aspecto ao distinguir os tipos de análise: a análise e identificação dos locais onde os acidentes acontecem, a medida da incidência dos acidentes para, não apenas elaborar as medidas preventivas, como também para prever seus efeitos, a análise da frequência e da gravidade dos acidentes com intuito de enfatizar ações preventivas, a identificação das causas diretas e indiretas do acidente.

A abordagem contemporânea ou sistêmica trouxe inovações consideráveis à análise, compreensão e prevenção dos acidentes de trabalho, na medida em que o homem é considerado o centro de um sistema mais complexo e o acidente é um evento particular do sistema homem/máquina, do sistema sócio-técnico. Nessa concepção, o acidente é um evento e não é mais tratado como algo isolado ou um simples produto de determinado fenômeno (LEPLAT, 1998; HALE e GLENDON, 1987; CHESNAIS, 1990), mas como resultante de interações entre os diferentes componentes de um sistema (um processo produtivo, por exemplo).

Nessa nova abordagem de segurança dos grandes sistemas tecnológicos, é postulada a criação de defesas duradouras para: a) localizar e neutralizar os erros dos operadores que são as fragilidades intrínsecas do sistema e b) tolerar os erros dos operadores, criando meios para que as falhas não provoquem acidentes. O erro é considerado como algo inerente ao processo e que requer controle por 
parte de toda a empresa desde os profissionais responsáveis pela concepção dos sistemas, os administradores, profissionais da área de segurança até o operador (que possivelmente é a parte mais frágil e diretamente afetada pelo acidente de trabalho).

Há autores como Hale (1998) que consideram que os avanços importantes ocorridos nos estudos para compreensão dos acidentes de trabalho foram fortemente influenciados pelo desenvolvimento da psicologia cognitiva. Para eles, essa ciência contribuiu para destacar as pessoas como processadores de informações e que respondem ao seu meio ambiente e aos perigos tentando identificar e controlar os riscos existentes. Dessa forma, deixa de culpar o trabalhador por erros e enfatiza as inadequações entre as demandas comportamentais do trabalho ou do sistema e as possibilidades para gerar e organizar comportamentos.

Muitos métodos foram desenvolvidos ns últimos anos com intuito de compreender a ocorrência de acidentes de trabalho. Um deles é o método MADS - MOSAR que foi criado por Dos Santos e Périlhon (2000). Esse acrônimo significa "Méthode d'Analyse des Dysfonctionnements Méthode Organisée et Systémique d'Analyse de Risques". Com ele, é possível apreender (identificar, avaliar e reduzir) eventos não desejados de uma planta industrial e identificar os meios de prevenção necessários para neutralizá-los. Em um segundo momento, permite definir os roteiros possíveis de acidentes em um dado contexto e avaliar a gravidade provável de seus efeitos. O MADS - MOSAR é baseado em uma modelização do processo de perigo que se decompõe em um campo, um sistema fonte e um sistema alvo. A utilização desse modelo para compreensão dos acidentes de trabalho é coerente com os pressupostos da abordagem contemporânea, pois é contemplada uma visão sistêmica do contexto no qual o trabalhador está inserido.

\subsection{Acidente de trabalho e algumas de suas causas}

Existem muitos conceitos de acidente citados na literatura, sendo que os autores concordam que ele pode ser considerado um evento não desejado que causa prejuízo à integridade das pessoas ou acarreta danos em sistemas técnicos e/ou sistemas ecológicos. Um conceito que pode ser aqui citado é "um evento não planejado e inesperado que pode (ou não) causar morte, lesão, dano ou perda. A tendência atual é reconhecer a importância da força e liberação de energia na causa de um acidente" (GRAYHAM, 1999).

Sobre o conceito de acidente de trabalho, é encontrado na literatura também aquele que foi citado por Zocchio em 1971, citado por Dela Coleta (1991, p.16). Sob tais considerações, o acidente pode ser definido por "todas as ocorrências não programadas, estranhas ao andamento normal do trabalho, das quais poderão resultar danos físicos e/ou funcionais ou morte ao trabalhador e danos materiais e econômicos à empresa". Como causas de acidentes podemos citar aquelas externas ao trabalhador (má concepção dos sistemas, ausência ou insuficiência de assistências técnicas) e causas internas (fadiga, estresse físico e/ou psíquico, excesso de confiança). Assim, pode dizer que o acidente de trabalho é um fenômeno que tem muitas causas e caracteriza-se como um evento súbito, inesperado e imprevisível.

Para explicar as causas do acidente de trabalho, Skiba (1973) desenvolveu a Teoria dos Portadores de Perigos na qual os fatores do sistema são classificados em pessoa e objeto. O perigo é considerado uma energia danificadora que, se ativada, pode provocar danos corporais (lesões) e/ou danos materiais. Essa energia pode estar associada a uma pessoa como, por exemplo: escorregões de trabalhadores em pisos molhados, torções nos pés, esbarrar em objetos parados. Essa energia pode ser relacionada a objetos, como nos seguintes exemplos: ferramentas afiadas, superfícies com temperaturas muito elevadas, guindaste com pesos suspensos. Dessa forma, para Skiba (1973), os fatores do sistema de trabalho: pessoa e objeto podem ser portadores de perigos em diversas situações.

Para Firenze (1978), há diversas causas prováveis dos acidentes: "omissão ou mau funcionamento do sistema gerencial: um fator de trabalho presente na situação, por exemplo, instalações, ferramentas, equipamentos e materiais; o fator humano (seja referente ao trabalhador ou a outra pessoa), fatores de meio ambiente como ruído, vibração, temperaturas extremas e iluminação." Enfim, é possível compreender que esse autor, nessa época já tinha uma visão mais ampla dos aspectos determinantes na ocorrência de acidentes de trabalho. 
Kirchner (1980) complementa a tese de Skiba (1973) ao fazer uma distinção entre perigo associado a objetos (perigo direto) e perigo associado a pessoas (perigo indireto). Na segunda situação, a pessoa periclitante, ou seja, aquela que corre perigo devido à energia danificadora que ela está portando naquela situação entra em contato direto com as condições de risco. Um exemplo seria o escorregão em piso molhado. A pessoa portadora da energia entrou em contato direto com a condição de risco que é a superfície molhada e escorregadia.

Se a energia, considerada pelo autor como danificadora, associada a uma pessoa (trabalhador) ou a um objeto de trabalho for ativada, ocorrerá uma colisão entre essa pessoa e o objeto caracterizando o acidente. Nessa abordagem, um acidente é considerado uma colisão repentina e involuntária entre pessoa e objeto causando danos corporais (lesão ou até mesmo morte) e/ou danos materiais à empresa. Para que essa colisão ocorra, muitos fatores poderão estar presentes. Um acidente com corte em uma ferramenta afiada poderá acontecer a partir do momento em que ocorre um mau uso da mesma, ela ser segurada de mau jeito, ser usada para um fim no qual ela não está destinada naquela circunstância como uma faca ser usada no lugar de uma chave de fenda. No modelo explicativo de Kirchner (1980) para a gênese dos acidentes de trabalho, a partir da Teoria dos Portadores de Perigos, ele busca evidenciar as relações entre os fatores determinantes da ocorrência de acidentes do trabalho para propor medidas que possam preveni-los. Nesse modelo, tanto a pessoa quanto o objeto ou ambos podem ser portadores de perigos e, a cada um, está associada uma energia danificadora que é resultante da diferença entre a energia atuante (a energia potencial que fica ativa) e a resistência específica do corpo da pessoa a essa energia. Quando a energia é nula ou negativa ela não tem efeito maléfico sobre a pessoa. Essa neutralização poderá ocorrer a partir do uso de EPI's (equipamentos para proteção individual).

Perrow (1985), ao analisar os empreendimentos perigosos, conclui que, independentemente dos dispositivos de segurança, há uma forma de acidentes que é inevitável tornando desfavorável a implantação de usinas nucleares, transporte marítimo de cargas tóxicas ou explosivas. Em processos produtivos com essas características, é impossível controlar e prever todas as circunstâncias para a concepção de um sistema infalível de segurança.

Sob as considerações desse autor, criam-se sistemas cada vez mais perigosos à medida que a tecnologia se amplia, que as guerras aumentam. Esse perigo não se restringe apenas aos que operam tais sistemas produtivos, mas se estende também aos passageiros, aos expectadores inocentes e também às gerações futuras. Ele faz afirmações coerentes e interessantes em relação ao fato de que, só se propõe soluções para reduzir ou eliminar os perigos desses processos à medida que eles são compreendidos. É claro que para entendê-los, é necessário investir tempo e pesquisas, colhendo informações detalhadas a respeito das características de suas concepções, quais os procedimentos e normas para funcionamento, conhecimento e habilidades básicos necessárias para operá-los e outros fatores.

Os sistemas perigosos possuem características especiais como, por exemplo, a forma como as situações que não vão bem podem interagir entre si, ou seja, a maneira como o sistema é interligado. Quando ocorre interação inesperada de dois ou mais defeitos entre os componentes é muito difícil alguém compreender o que está acontecendo nesse momento. Assim, fica muito difícil agir para recuperar a falha inicial. Ela poderá se propagar rapidamente. Uma ação dos trabalhadores nesse momento poderá até piorar a situação devido ao desconhecimento inicial em relação ao problema. Quanto mais o sistema for complexo e interligado, maiores as chances de ocorrerem grandes catástrofes devido à dificuldade em ver e compreender o que está ocorrendo para atuar no início da falha.

A abordagem sobre acidentes de trabalho de Perrow (1985) é coerente com a de Reason (1993) que será detalhada mais adiante no espaço desse artigo. Os pontos em comum dessas duas abordagens são: a) reconhecimento da participação da forma como um sistema produtivo foi concebido no surgimento de acidentes; b) o erro é inevitável, estando na gênese de acidentes de trabalho. Nessa perspectiva, o primeiro autor supracitado afirma: "eu tenho certeza de que os operadores erram, exatamente da mesma maneira que os projetistas, as elites e os professores de sociologia erram. Mas os operadores geralmente ganham uma má publicidade: as elites, que são a causa da construção desses sistemas, e os projetistas raramente" (PERROW, 1985, p.93).

O terceiro ponto em comum é relacionado à interação dos defeitos. Para os autores, os defeitos independentes uns dos outros interagem de maneira imprevista em um sistema ocasionando o acidente. 
É preciso salientar que a operação de tecnologias complexas e perigosas fora do contexto no qual elas foram concebidas, como no caso de importação de máquinas e equipamentos, é outro agravante na questão da exposição a erros e, consequentemente a acidentes de trabalho. Nessas circunstâncias podem ocorrer dificuldades no domínio do idioma trazendo transtornos e incoerências na compreensão dos manuais para operação de máquinas.

Bley (2004) relata que a não percepção do risco de acidentes pode expor o trabalho à sua ocorrência, mas a percepção do risco por si só não garante a adoção do comportamento seguro. Mesmo percebendo que a situação é perigosa, o trabalhador poderá optar por realizá-la a partir de diversos fatores: pressão da empresa por produtividade, necessidades financeiras do trabalhador (possivelmente ele percebe aquela oportunidade de trabalho como a única naquele momento que pode garantir suas despesas básicas e de sua família), despreocupação da empresa na adoção de medidas de segurança, enfim, muitos outros aspectos que interagem nesse contexto e influenciam na exposição do trabalhador aos riscos das situações de trabalho.

Vemos situações como essa ocorrendo com muita frequiência não apenas no Brasil, mas também em empresas no exterior. Haja vista a situação que foi amplamente veiculada na mídia, dos mineiros no Chile que foram soterrados em uma profundidade impressionante, de aproximadamente setecentos metros, quando realizam as atividades laborais. Para resgatá-los foram investidos meses de trabalho. Ao submeterem-se a essa situação perigosa, eles tinham consciência do perigo, entretanto, a necessidade financeira, possivelmente, sobressaiu no momento da escolha em aceitarem realizar tal trabalho.

A adoção de um comportamento seguro é algo muito complexo e resultante de questões internas ao trabalhador (vontade, disposição, motivação, percepção de riscos, etc.) e do ambiente de trabalho (informações claras e acessíveis, instalações técnicas precárias ou modernas, comunicações transparentes nas equipes, condições técnicas seguras e outros). Essas questões estão interagindo constantemente e poderão contribuir positiva ou negativamente na adoção de um comportamento seguro por quem está inserido nesse contexto.

\subsection{Percepção de risco de acidentes}

O acidente deve ser visto como sinal de disfunção sistêmica, como oportunidade para aprendizado organizacional e caminhos para aperfeiçoamento desse sistema (REASON, 1997; REASON \& HOBBS, 2003; WOODS \& COOK, 2002). Nesse contexto, a percepção do risco assume um papel importante, uma vez que o comportamento seguro requer identificação e controle dos riscos.

Perceber é um conceito que vem sendo considerado como mais um elemento importante para a compreensão dos aspectos psicossociais relacionados à prevenção dos acidentes de trabalho, em pesquisas de profissionais da psicologia (BLEY, 2004). Na prática, há uma grande lacuna por parte das organizações quando não buscam conhecer o nível em que se encontra a percepção de risco pelos seus trabalhadores.

Para uma melhor compreensão do conceito de percepção de risco é preciso retomar conhecimentos básicos sobre as sensações. $\mathrm{O}$ contato que o ser humano estabelece com o mundo externo é mediado pelos seus sentidos (tato, olfato, audição, visão e paladar), por meio dos quais os dados da realidade são recebidos e ganham significados. O processo de receber e converter o estímulo externo é chamado de sensação, enquanto que o processo de atribuição de sentido à informação recebida é chamado de percepção.

Pode-se dizer que o erro humano tem potencial para gerar acidente de trabalho, assim, a seguir, essa questão da percepção do risco será aprofundada a partir de uma abordagem apresentada por Amalberti (1996) sobre a autodetecção de erros.

\subsubsection{Relação da metacognição com a autodetecção dos erros}

O erro pode estar na origem do acidente de trabalho. Ele é algo que sai do controle da pessoa fazendo com que ela não atinja o resultado esperado quando se propõe a realizar uma tarefa. $\mathrm{O}$ erro está relacionado ao desempenho diferente daquele pretendido. Quando se planeja atingir um objetivo e 
não consegue, por uma série de motivos: problemas na manipulação das informações, no planejamento, esquecimento de alguma ação (ou lapso de memória) e outros.

O erro humano é inevitável e resultado das interações de diversos fatores no contexto de trabalho (REASON, 1993; AMALBERTI, 1996). Ao realizar análise da atividade, principalmente dos pilotos de avião, Amalberti (1996) concluiu que a questão importante no estudo do erro é compreender a autodetecção, isto é, como o trabalhador recupera os próprios erros. Suas contribuições para a discussão proposta nesse artigo estão relacionadas aos conceitos de metacognição, autodetecção de erros e compromisso cognitivo, pois sua intenção é mostrar uma ótica produtiva dos trabalhadores a partir da promoção da segurança e não uma visão crítica relacionada à busca de culpados por falhas e erros. Nessa perspectiva, Amalberti (1996) propõe que o trabalhador possui mecanismos cognitivos que lhe asseguram um compromisso cognitivo que visa: a) sua segurança e a do sistema, b) o bom desempenho e c) minimizar as conseqüências fisiológicas indesejáveis como o estresse. Para atingir esses objetivos, o trabalhador possui uma visão reflexiva de suas próprias capacidades que é designada pela psicologia de metacognição.

A metacognição envolve dois aspectos: a) o conhecimento acerca da cognição. Ele diz respeito à informação que o trabalhador tem de seus recursos cognitivos e, b) o autocontrole da cognição que tem a ver com o conhecimento de diferentes estratégias a serem usadas em contextos diferentes, mais a capacidade de detectar erros e contradições no trabalho e também a habilidade para separar a informação significativa da que não é significativa (NIST e MEALEY apud FLIPPO et al., 1991).

A metacognição está ligada à autodetecção na medida em que permite ao trabalhador recuperar as informações para identificar onde ele errou. Durante a jornada de trabalho, os profissionais detectam e corrigem muitos dos seus erros, tanto de forma consciente, quanto inconsciente. Sob essas considerações, Amalberti (1996) conclui que os erros mostrados nos relatórios das empresas constituem uma parcela muito pequena dos erros cometidos pelos profissionais, tendo em vista essa capacidade que eles possuem de detectar e corrigir os próprios erros. Assim, é importante compreender porque alguns erros não são detectados pelo trabalhador, ou seja, porque há uma parcela de erros que escapa do seu controle e aparece nos relatórios.

A detecção é iniciada por um controle metacognitivo do percurso que o trabalhador realizou e o que se esperava executar para obter uma boa resposta. A capacidade de detectar e corrigir erros é um componente essencial da resolução eficaz de um problema, mas não é suficiente para permitir ao trabalhador restabelecer seu equilíbrio cognitivo. Uma ação de detecção e recuperação forçada de erros pode expor o trabalhador à fadiga excessiva (AMALBERTI, 1996). Daí a necessidade de se analisar as condições reais nas quais o trabalho é desenvolvido e implantar ações para redução de danos à saúde do trabalhador, não apenas do acidente em si, mas principalmente, de desgastes que ocasionam a fadiga física e psíquica e dificultam o exercício do compromisso cognitivo.

O autor concorda nos aspectos relacionados aos controles cognitivos (atencional e automático) propostos por Reason (1987) e aponta que o sistema cognitivo comete erros não propositais, mas aceita determinados erros para se economizar, pois os automatismos (controle cognitivo automático) são menos custosos para o operador do que comportamentos baseados em regras. Em situações nas quais o trabalhador reconhece que não traz graves conseqüências, ele aceita cometer erros e os detecta depois, uma vez que, para ele, é menos penoso agir assim do que utilizar-se de um funcionamento consciente, lento, fatigante e controlado por regras (AMALBERTI, 1996).

Em circunstâncias como essa, "o trabalhador não age de forma puramente mecânica, ele adota certa vigilância através de um compromisso cognitivo para não cometer erros" (AMALBERTI, 1996:261) de maneira que ele consegue exercer certo controle para não deixar ocorrer erros que tragam conseqüências desastrosas. Porém, "os processos de detecção do erro podem ser falhos porque possuem muita sensibilidade à similaridade e freqüência dos estímulos que o trabalhador encontra no seu cotidiano" (REASON, 1993:186), assim quando os erros acontecem é porque houve "desregulação nesse compromisso cognitivo" (AMALBERTI, 1996:316).

Amalberti (1996) recorre ao modelo do "queijo suíço" de Reason (1993) para explicar as proteções cognitivas em série e aponta que a cognição dinâmica é como um sistema multiplacas. E acrescenta um aspecto não mencionado por Reason: as defesas são interdependentes e mantém interações importantes. Essas interações são dirigidas pelo metaconhecimento e pela confiança. $\mathrm{O}$ autor traz o conceito de compromisso cognitivo, sendo esse definido como " um mecanismo através do qual o trabalhador busca atingir o objetivo desejado, com menos riscos (externos e internos), imediatos 
e futuros (evitar esgotamento)" (AMALBERTI, 1996:261). Ele tem a ver com os objetivos de continuidade (RASMUSSEN, 1990 apud AMALBERTI, 1996) que se dividem em objetivos: a curto prazo (evitar erros e situações fatais) e a longo prazo (preservar o sistema biológico contra fadiga e esgotamento). Esse compromisso cognitivo leva em conta uma representação do risco externo de acidente nos procedimentos em curso, o nível de exigência do resultado a atingir, uma representação de seus próprios recursos, de seu estado de fadiga, de suas capacidades e de muitos outros elementos.

O sistema cognitivo do trabalhador está relacionado a um retorno de informação que permite tomar consciência do comportamento e, quando necessário, ajustar as intenções em função do desempenho observado em situações inesperadas. "Esse sistema se utiliza do compromisso cognitivo e da segurança natural ou ecológica para se adaptar e se proteger para não sair dessa área de regulação" (AMALBERTI, 1996:315). É essa área que permite retomar as informações e realizar os ajustes que se fizerem necessários. Os erros que surgem em um sistema podem fazer parte dessa adaptação e não serem considerados apenas critérios da fragilidade humana. Os erros são elementos que revelam perda no controle do compromisso cognitivo. O sistema cognitivo pode desregular-se e sair das áreas nas quais domina a situação. $\mathrm{O}$ sintoma dessa desregulação não é cometer erros, mas não mais conseguir detectá-los e recuperá-los. Assim eles aparecerão ao observador externo. Nesse contexto, as defesas podem não funcionar por muitos motivos como: a falta de competência, de tempo, questões emocionais (estresse, desmotivação).

Tanto Reason (1993) quanto Amalberti (1996) concordam que os erros fazem parte da rotina dos trabalhadores, ou seja, são inevitáveis. Enquanto Reason (1993) propõe uma gestão dos erros a partir da identificação e correção das condições latentes, a abordagem de Amalberti (1996) sugere proporcionar condições para a pessoa detectar seus próprios erros, pois, segundo ele, os melhores trabalhadores não são os que não cometem erros, mas aqueles que conseguem recuperar os erros cometidos. Sob suas considerações, o erro é um sintoma das fragilidades nas proteções internas do funcionamento cognitivo. O trabalhador é inteligente, muito flexível e adaptável, além de frágil e limitado em seus processos cognitivos. Ele sabe dessas suas características, ou seja, ele possui o metaconhecimento, assim, desenvolve uma série de proteções cognitivas para conferir coerência, eficácia e segurança em seu desempenho. $\mathrm{O}$ autor acrescenta que é preciso ir além da análise do erro e também dos processos cognitivos que evitam os erros em situações de normalidade (que não foram aprofundados aqui) e ter acesso à globalidade das interações que ocorrem dentro de uma empresa e também reconhecer que os riscos não podem ser suprimidos, apenas geridos.

Para que ocorra essa gestão de erros, dentre outros aspectos, a empresa deve dar uma atenção especial aos apoios instrumentais que ela disponibiliza aos trabalhadores, pois os instrumentos auxiliam a organização das atividades cotidianas na medida em que servem de suportes à atenção e memória "(representações internas), além das representações externas (do ambiente)" (NORMAN et al., 1994:3 e HUTCHINS, 1994:460). Quando se utiliza os instrumentos, aproveita melhor o tempo, pois eles permitem uma recuperação rápida de muitas informações da memória de longo prazo. Os instrumentos de trabalho podem também auxiliar na prevenção de acidentes de trabalho como, por exemplo, computadores de bordo em aviões que auxiliam o fornecimento de informações exatas aos pilotos (SOARES, 2011).

\subsection{Gestão do risco pelo trabalhador}

Essa gestão é mais complexa do que se imagina, pois envolve o que Amalberti (1996) denomina de compromisso cognitivo, cujo significado foi citado anteriormente, mas que vale a pena retomar, dada a sua importância para a discussão em questão. Esse mecanismo é, segundo o autor, algo que envolve mecanismos cognitivos que asseguram ao trabalhador um compromisso eficaz composto por três objetivos: a segurança própria e a do sistema, o bom desempenho (que é imposto, mas muitas vezes, é também desejado) e a minimização de suas conseqüências fisiológicas e mentais (fadiga, estresse, esgotamento físico e/ou mental).

Na administração do compromisso cognitivo, são envolvidas as exigências da situação e a visão reflexiva das capacidades do trabalhador. Essa capacidade humana de tomar consciência daquilo 
que já sabe é designada pela psicologia de metacognição. Aqui são consideradas as competências do trabalhador e a questão de que, a todo momento, acontece no mundo uma espécie de risco que é preciso gerir. O risco em questão não é apenas referente a acidente de trabalho, mas ao risco cognitivo da escolha de um mau compromisso e, depois expor-se a fadigas excessivas durante a jornada de trabalho, desempenho insuficiente ou até mesmo ao risco de perder o controle da situação e, de repente, perder o emprego devido a atuação incoerente com o esperado pela empresa.

A partir dessa perspectiva sobre percepção de riscos, autodetecção e gestão de erros, uma pergunta é feita, nesse momento: é possível ensinar comportamento seguro? Ou será que o trabalhador vai aprendendo como adotá-lo à medida que vai realizando suas escolhas? Isto é, ele aprende a gerir o risco quando está inserido no contexto de trabalho e tem condições de realizar escolhas reais. Outra questão que pode ser colocada é: o que é comportamento seguro a partir desse ponto de vista? A questão do comportamento seguro toma uma dimensão mais ampla, considerando os aspectos que compõem o compromisso cognitivo. Assim, o ato denominado inseguro por alguns profissionais da área de segurança do trabalho, nem sempre poderia ser assim denominado. Possivelmente, ao deixar de usar determinado EPI (equipamento de proteção individual), o trabalhador o fez conscientemente optando por melhorar seu desempenho em detrimento de sua própria segurança. Nessa abordagem, o ato inseguro é resultado de uma dificuldade de administração dos aspectos componentes do compromisso cognitivo pelo trabalhador. Dessa forma, ensinar comportamento seguro pode estar relacionado à instrução acerca de como se faz a gestão do risco, considerando que esse é inevitável em muitas circunstâncias, não apenas naquelas laborais.

Talvez esse processo de auxiliar o trabalhador nessa gestão do risco deverá acontecer com esclarecimentos e conscientização a respeito das reais consequiências de suas escolhas, para si, para os colegas, para a empresa. Essa, por sua vez, deve estar envolvida no processo de prevenção de acidentes e sua participação deverá envolver a minimização da contradição existente no compromisso cognitivo: segurança do trabalhador, bom desempenho e redução das consequências fisiológicas do trabalho sobre a saúde física e psíquica do trabalhador. Apenas ensinar comportamento seguro não basta. É necessário a empresa investir em ações para tornar as condições laborais favoráveis à adoção desse comportamento.

Nessa abordagem, o erro humano não é uma manifestação negativa do comportamento humano, mas sim, algo provável de ocorrer em qualquer contexto. É preciso envidar esforços conjuntos nas equipes para estudar possibilidades para redução da ocorrência do erro humano e, consequentemente, de acidentes.

\subsection{Contribuições da Clínica da Atividade à segurança do trabalho}

Yves Clot é francês e desenvolve estudos buscando compreender o lugar da subjetividade na análise do trabalho. A Clínica da Atividade (Clinique de l'Activité) é um método criado por ele para análise e compreensão do trabalho. São propostos conceitos importantes como: real da atividade, gênero da atividade e estilo da ação, sendo que o primeiro se refere à atividade do indivíduo sobre si. Para Yves Clot, a atividade não é uma mera reação, mas sim um filtro subjetivo que proporciona um sentido para a vida da pessoa que a executa. Esse sentido que é dado por ela é diferente daquele pensado por quem a concebeu.

O real da atividade é aquilo que pode ser feito, mas não se faz, ou seja, as atividades suspensas, contrariadas, sem possibilidades de realização. Enquanto a atividade realizada é o que se faz, o real da atividade é o que não se pode fazer, o que se gostaria de fazer, o que poderia ter sido feito e até mesmo o que se faz para não fazer aquilo que deve ser feito.

O gênero da atividade é um sistema de instrumentos, construído coletivamente e que se encontra no interior da atividade individual. Ele pode ser constituído de atividades encorajadas ou proibidas. É um repertório que organiza antecipadamente a atividade. É um instrumento coletivo da atividade individual conhecido somente por aqueles que participam da mesma situação. Em suma, o gênero é o que é permitido e o que é proibido em um determinado contexto de trabalho, representando uma memória que se refere ao passado e possibilita prever o futuro permitindo evitar possíveis erros no exercício da atividade de trabalho. 
O estilo aparece quando o trabalhador pode falar do seu trabalho, do saber fazer, mobilizando a variabilidade e faz circular as variantes. Ele tem um conteúdo individual, englobando as habilidades desenvolvidas pelo trabalhador ao enfrentar situações novas e dificuldades na sua rotina de trabalho.

Nas considerações de Clot (2006), se o gênero degenera, o desenvolvimento da atividade fica bloqueado, configurando uma situação de risco. Se ocorrer degenerescência do gênero, pode degenerar a atividade, favorecendo o desenvolvimento de patologias e o aparecimento de acidentes de trabalho. Isso acontece porque o trabalhador fica isolado e impossibilitado de mobilizar o recurso genérico e sem o suporte do coletivo.

A abordagem desse autor frisa a importância do coletivo na atuação profissional e, principalmente, na atuação segura em situações laborais. Esse coletivo não é apenas uma coleção de pessoas, mas a fonte de uma história comum partilhada que é consultada pelo trabalhador antes de tomar decisões. Ao mesmo tempo em que ele permite à pessoa desenvolver, o coletivo lhe impõe certos limites, uma vez que, o trabalho comporta possibilidades de engano. Dessa forma, segundo Clot (2006), trabalhar é sempre correr o risco de errar.

Para ilustrar a questão da degeneração do gênero de atividade com a conseqüente predisposição à ocorrência de erros, Lima (2007) cita o estudo de Ferreira \& Iguti (1996). Esses pesquisadores destacaram dois aspectos que diferenciavam a política de pessoal e a gestão da mão-deobra adotada por uma empresa na época do estudo e no passado: a terceirização dos serviços e a diminuição do efetivo operacional.

Os referidos pesquisadores constataram que os dois aspectos supracitados ocorreram de forma precária e algumas das conseqüências negativas deles são: o aumento das desigualdades, maior exposição aos riscos, impedimento do acúmulo de conhecimentos e a consolidação de compromissos entre os membros das equipes devido ao caráter temporário dos contratos. Esses fatores aumentam as possibilidades de ocorrência de acidentes.

Lima (2007) retoma a questão de os acidentes de trabalho serem fenômenos complexos e resultantes de diversos fatores que merecem ser considerados ao analisar a gênese do acidente.

\section{A segurança comportamental como um caminho para ampliar a visão do acidente de trabalho}

A questão da segurança comportamental está relacionada a "o que e como fazer para que as pessoas se cuidem enquanto trabalham". Ela se refere à aplicação dos conhecimentos científicos da Psicologia Comportamental na segurança do trabalho, com foco nos comportamentos observáveis, enfatiza o comportamento seguro e não a punição ao trabalhador que agiu de forma insegura.

Meliá (1999) define a Psicologia da Segurança no Trabalho como "a parte da psicologia que se ocupa do componente de segurança da conduta humana". É uma ciência que vem se desenvolvendo desde a década de 70 . Pode ser abordada também enquanto um conjunto de técnicas (metodologia de intervenção) que permite compreender e agir sobre os elementos humanos para prevenir acidentes de trabalho de forma eficaz. Essa abordagem da psicologia tem potencial para complementar as práticas dos profissionais que atuam em segurança no trabalho.

Embora essa nova forma de gestão em segurança do trabalho venha crescendo na Inglaterra, Austrália e Estados Unidos, no Brasil ainda são escassos os materiais sobre as contribuições da Psicologia na Segurança do Trabalho. Mesmo assim, é possível encontrar obras preciosas como Acidentes de Trabalho - Fator Humano, Contribuições da Psicologia do Trabalho, Atividades de Prevenção, do psicólogo José Augusto Dela Coleta publicado em 1991 e Comportamento Seguro da psicóloga Juliana Zilli Bley de 2004.

Coleta (1979) é um dos pioneiros dessa abordagem. Ele aponta a importância da psicologia no cenário da produção cientifica e nas investigações sobre a questão do acidente de trabalho e alerta os psicólogos brasileiros para a necessidade de produzirem conhecimentos científicos sobre essa questão. Enquanto que Bley (2004) aborda a necessidade de aprendizagem de comportamentos seguros nas atividades de risco. A autora revela lacunas no processo de educação para a segurança no aspecto comportamental. Sua pesquisa traz apontamentos em relação a treinamentos e palestras de segurança que tinham como objetivo promover comportamentos seguros no trabalho, atividades essas realizadas em duas indústrias metalúrgicas situadas no Paraná. Suas conclusões relatam a importância de trabalhar a prevenção de forma adequada em treinamentos, palestras e outros eventos nas empresas. 
A autora reforça a importância de lidar com o comportamento humano de forma científica, cuidando para que não caia no senso comum. Para ela, o comportamento é algo complexo compreendendo relações que o individuo estabelece com seu ambiente de trabalho. Nesse contexto, a prevenção envolve a participação dos trabalhadores dando-lhes poder. Assim desmente que trabalhar com o comportamento preventivo em segurança é manipulação, conforme afirmam alguns críticos da psicologia comportamental.

A literatura sobre acidentes de trabalho aponta para muitas mudanças físicas, tecnológicas e informacionais que vem ocorrendo para redução dos acidentes de trabalho. Os resultados, embora positivos, ainda não são suficientes para se afirmar que é frequente a prática do comportamento seguro, principalmente em empresas brasileiras. O ser humano é o responsável por esse comportamento, seja ao projetar uma máquina, dispositivo ou ao operá-los. Mas o que é comportamento seguro? Será fácil defini-lo em todas as circunstâncias de trabalho? Se aos pesquisadores essa questão é difícil, imagine para os trabalhadores.

O grande desafio para os profissionais que trabalham na prevenção de acidentes de trabalho está em definir esse comportamento, ensinar, aperfeiçoar e até mesmo desenvolver técnicas que permitam a conscientização e motivação para a prática constante do comportamento seguro em situações de trabalho e outras que podem significar riscos à integridade física do ser humano.

Para a Psicologia, compreender a influência humana na ocorrência de acidentes de trabalho deve considerar os comportamentos, principalmente a forma como o indivíduo se relaciona com seu meio de trabalho. Nessa perspectiva, Coleta aponta que:

"os comportamentos, as atitudes e as reações dos indivíduos em ambiente de trabalho não podem ser interpretados de maneira válida e completa sem se considerar a situação total a que eles estão expostos, todas as inter-relações entre as diferentes variáveis, incluindo o meio, o grupo de trabalho e a própria organização como um todo. Acidente de trabalho, neste sentido, pode ser visto como expressão da qualidade da relação do indivíduo com o meio social que o cerca, com os companheiros de trabalho e com a organização" (COLETA, 1991, p. 77).

Nas considerações de Meliá (1999), os modelos de análise funcional da conduta humana permitem identificar os elementos que sustentam as condutas inseguras e os que sustentam ou poderiam sustentar as condutas seguras. Para esse autor, é possível aplicar a Análise do Comportamento para a prevenção de acidentes. Ela permite perceber desequilíbrios de situações contrárias às condutas seguras e favoráveis às condutas inseguras.

Estudar acidentes de trabalho considerando apenas que alguém errou e, normalmente, apontando o acidentado como culpado não faz sentido e impossibilita a tomada de medidas eficazes para prevenir novas ocorrências de acidentes. É imprescindível que consiga identificar quais as situações que estão favorecendo as condutas inseguras.

Ao trabalhar com prevenção de acidentes, os tipos de comportamentos normalmente citados pelos profissionais da segurança são aqueles ditos seguros e os inseguros. O adjetivo "seguro" é utilizado por tais profissionais para se referir àquilo que o trabalhador faz e que contribui para a não ocorrência de acidentes como, por exemplo, o cumprimento de normas de segurança. Os comportamentos ditos inseguros são aqueles que contribuem para que os acidentes aconteçam. A desconsideração em relação aos procedimentos de segurança é um exemplo de ato inseguro.

Em sua pesquisa, Bley (2004) comparou respostas de instrutores de treinamento de segurança de duas metalúrgicas e de funcionários participantes dessas atividades. A autora conclui que há divergências entre o que os dois grupos (instrutores e funcionários) entendem por comportamento seguro. $\mathrm{O}$ que os instrutores e funcionários consideram como significado de comportamentos seguros é divergente entre si e também está distante do conceito. Os dados encontrados confirmam também a grande variedade de generalidade dos termos utilizados tanto por instrutores quanto por funcionários para definir o conceito. Isso é uma questão bastante crítica porque confirma que há pouca clareza sobre o que caracteriza o comportamento seguro podendo causar prejuízo ao processo de capacitação desses funcionários para prevenir acidentes de trabalho. Nos casos estudados por Bley (2004), considerando a análise do comportamento e os princípios do processo ensino-aprendizagem, é muito 
difícil os funcionários que participaram dos treinamentos adotarem comportamentos seguros, pois não estão sendo instruídos adequadamente para essa prática.

A referida autora, ao abordar o Comportamento Seguro, afirma que ele está relacionado à capacidade de uma pessoa identificar e controlar os riscos presentes numa atividade atual, de forma a reduzir a probabilidade de ocorrências indesejadas no futuro, para si e para os outros. Para a autora, é essa competência que deve ser desenvolvida e estimulada nos processos educativos para que ocorram cada vez mais comportamentos seguros nos locais de trabalho. Ela complementa que devem ser dadas condições ao trabalhador para pensar, sentir e agir, considerando os riscos aos quais ele está exposto e as melhores formas de controlá-los. Possivelmente tais questões tem relação com a expressão consciência para a prevenção que muitos profissionais da área da segurança utilizam no cotidiano laboral.

Realizar intervenções em segurança comportamental requer um planejamento cuidadoso e detalhado por parte dos gestores, profissionais da segurança do trabalho e demais interessados. Esse processo demanda um prazo para aplicação de procedimentos que pode variar de algumas semanas até meses, dependendo do tamanho e da complexidade da intervenção. Segundo os autores dessa abordagem, por se basear em um modelo científico, as intervenções em segurança podem proporcionar resultados significativos e duradouros, desde que certas condições sejam estabelecidas. Aqui está incluso o comprometimento das partes envolvidas, inclusive dos operadores que, normalmente são as partes diretamente afetadas pelas ações e devem ser agentes (atores) nesse processo.

De uma forma mais sintetizada, o modelo de segurança comportamental na prática, se baseia, entre outras técnicas, no uso de observação por pares, estabelecimento de metas e feedback (que podem ser apresentados em forma de gráficos ou relatórios que representam o desempenho coletivo). Há ênfase no cuidado mútuo da segurança, de tal forma que se cria uma cultura de segurança na qual ocorre o cuidar-se ativamente, ou seja, eu estou atento à segurança dos demais como os demais estão atentos a minha.

O desenvolvimento e também o aperfeiçoamento do comportamento seguro está diretamente relacionado à questão da educação para a segurança. Essa questão será aprofundada nos tópicos seguintes.

\section{4. É possível incentivar comportamentos seguros?}

A partir da abordagem da Segurança Comportamental de Bley (2004), os treinamentos, cursos, palestras, procedimentos e políticas são importantes estratégias para a promoção da mudança de comportamentos de risco para comportamentos seguros, desde que se tenha clareza de quais são os comportamentos de risco existentes, quais os comportamentos seguros que se deseja estimular na prática dos trabalhadores, o que faz com que as pessoas ajam desta forma e o que é preciso fazer para tornar a mudança desejável pelas pessoas. Sem essas considerações, as mudanças comportamentais são impossíveis.

Sob as considerações de Bley (2004), os diálogos de segurança, as abordagens de conscientização, as palestras, os treinamentos, os cartazes e as campanhas de prevenção são muito apresentados como ações educativas aos trabalhadores, mas nem sempre surtem o efeito desejado. Em algumas circunstâncias, esses mecanismos parecem ter sido concebidos para dar ordens ao invés de educar os trabalhadores, público alvo dessas técnicas. As mensagens comumente encontradas em áreas de produção das empresas como use o cinto, previna-se, uso obrigatório do cinto de segurança, ou mesmo, imagens de olhos perfurados por pregos, pessoas queimadas, carros destruídos acompanhados por sangue no asfalto, são algumas das estratégias utilizadas em tentativas de modificar a postura do trabalhador no que diz respeito à própria segurança. Entretanto, a frequência das ocorrências de acidentes de trabalho indica o insignificante e negativo resultado desse tipo de atuação. A partir dessa abordagem, o ensino de comportamentos seguros é mais amplo do que algumas empresas tem praticado.

\subsection{Ensino de comportamentos seguros}


Ensinar comportamentos seguros pode envolver a mudança das variáveis que compõem o comportamento, ou seja, estabelecer novas relações entre um organismo, o meio em que ele atua e as consequiências da sua atuação. Em situações de trabalho, essas questões se aplicam a partir de modificações nos equipamentos, na organização do trabalho, nas informações que são disponibilizadas aos trabalhadores, nas normas, em fatores interpessoais e socioculturais e ainda nas estratégias educativas utilizadas pela organização.

Nas considerações de Bley (2004) um dos grandes dilemas da educação para a prevenção consiste em encontrar um equilíbrio saudável entre obedecer às regras e agir com autonomia. Ensinar alguém a trabalhar com consciência de segurança é levá-lo a conhecer criticamente sua realidade, a fazer escolhas com relação a elas, considerando as conseqüências para si e para aqueles que o cercam. Dessa forma, o processo de conscientização e educação com foco na prevenção não pode ficar restrito ao nível da obediência. Ela enfatiza a importância de os instrutores dos treinamentos voltados para a segurança no trabalho estarem bem preparados, não apenas do ponto de vista técnico, mas também que haja uma formação didático pedagógica adequada à realização do processo de ensinar. Ela complementa com a questão de o processo de ensinar e aprender vai muito além das salas de aula e treinamento. É um processo contínuo e do dia a dia. Preocupar-se também com a capacitação desses profissionais é fundamental para o bom desempenho no processo de prevenção, pois eles participam da gestão organizacional. Educação é um processo importante que merece investimento constante por parte das empresas para que haja eficácia nos resultados por ela almejados.

\section{Comportamento Seguro e sua aplicação nos Sistemas de Gestão de SST}

As pesquisas desenvolvidas por Bley (2004) tem demonstrado que atualmente existem casos de práticas bem sucedidas em empresas (em diversas regiões do Brasil e em outros países) que podem demonstrar a efetividade desta modalidade técnica e científica de compreender e atuar sobre o comportamento humano e suas interfaces sobre os aspectos de segurança no trabalho. Dessa forma, a partir da perspectiva de Sistemas de Gestão, os conceitos relacionados com o Comportamento Seguro podem ser aplicados com objetivo de aperfeiçoar e, até mesmo, potencializar um programa amplo de Gestão de Segurança e Saúde. A partir de observações em relação à prática em muitas empresas, percebe-se que um dos principais desafios na implantação de um Sistema de Gestão é o comprometimento das pessoas envolvidas. Outro aspecto crítico é o monitoramento de resultados que aparece sob a forma de metas e indicadores para a medição do desenvolvimento do sistema como um todo e, em especial neste caso, do aspecto humano do processo. Algumas perspectivas de análise e aplicação permitem realizar o monitoramento do processo no que se refere ao comportamento seguro.

A partir de uma abordagem mais ampla, os indicadores humanos em segurança podem ser classificados em duas categorias básicas: os proativos e os reativos, sendo que os primeiros referem-se diretamente aqueles que buscam identificar os aspectos humanos antes do acidente de trabalho. Os reativos integram-se aos indicadores organizacionais que medem situações que já ocorreram como, por exemplo, o TFSA (Taxa de Freqüência de acidentes sem afastamento) ou o TFCA (Taxa de freqüência de acidentes com afastamento) (BLEY, 2004). Assim, entende-se que trabalhar na manipulação desses indicadores é algo mais complexo do que possa parecer, requerendo mais comprometimento e competência técnica por parte dos profissionais da segurança do trabalho em uma empresa. Para desenvolver atividades como os diálogos diários de segurança, palestras e treinamentos com objetivos de prevenção de acidentes e orientações para adoção de comportamentos seguros, os instrutores devem entender não apenas dos aspectos técnicos, mas também das questões comportamentais. Compreender algumas nuances referentes ao processo de aprendizagem do ser humano (como ele adquire e utiliza as informações para realizar as tarefas cotidianas), a memorização, as tomadas de decisão, suas dificuldades e limitações, as contradições existentes nos processos produtivos que nem sempre os administradores estão dispostos a mininizá-las e outra gama de fatores que podem interferir direta ou indiretamente nesse processo de prevenção de acidentes.

\section{Contribuições da ergonomia à prevenção dos riscos profissionais}


A ergonomia é uma prática de transformação (adaptação, concepção) das situações e dispositivos de trabalho. Ela tem uma finalidade prática (FALZON, 2007). Há muitos conceitos de ergonomia, mas há um que foi adotado em 2000 pela International ergonomics Association (IEA) é mundialmente aceito nos dias atuais:

"a ergonomia (ou Human Factors) é a disciplina científica que visa a compreensão fundamental das interações entre os seres humanos e os outros componentes de um sistema, e a profissão que aplica princípios teóricos, dados e métodos com o objetivo de otimizar o bem-estar das pessoas e o desempenho global dos sistemas" (FALZON, 2007).

Embora os vínculos da ergonomia com a segurança do trabalho tenham sido muito fortes na década de 1970 (FAVERGE, 1970), se afrouxaram nos anos seguintes (GARRIGOU et al., 2007). Essa duas abordagens são distintas, entretanto, seus vínculos podem ser estreitos devido à característica de complementaridade que elas possuem, pois seus objetivos estão relacionados à proteção da saúde dos trabalhadores a partir da redução desses da exposição à sobrecargas físicas, psíquicas e cognitivas, além de outros danos.

A articulação da ergonomia com abordagens voltadas à preservação da saúde do trabalhador se justifica pelo fato de que, normalmente, os riscos profissionais constituem um objeto difícil de ser decifrado e conhecido pelos atores do processo (trabalhadores, projetistas, administradores e profissionais da segurança do trabalho: engenheiros e técnicos). Às vezes, eles têm acesso a essas condições de risco de forma muito fragmentada.

O aspecto enigmático da exposição aos riscos leva os atores supracitados a obtenção de representações incompletas ou até mesmo contraditórias. Dessa forma, nenhum profissional sozinho consegue obter compreensão total de uma situação de exposição a riscos de adoecimento e/ou de acidentes e, consequentemente, elaborar ações eficazes para promover prevenção a danos aos operadores (GARRIGOU et al., 2007).

A contribuição da ergonomia nesse contexto pode ser explicada devido à sua utilização de técnicas como a análise da atividade que permite buscar os conhecimentos dos trabalhadores que são os atores diretamente atingidos pelas condições de trabalho. Ela articula conhecimentos subjetivos e objetivos dando oportunidade aos diferentes protagonistas laborais de se tornarem atores de sua abordagem para prevenção de danos.

Para aprofundar a discussão sobre a articulação da ergonomia com as demais abordagens que atuam com a prevenção de riscos profissionais, serão citados, a seguir, alguns conceitos fundamentais a partir de GARRIGOU et al., 2007:

a) Álea e evento não desejado: álea é um evento ameaçador, ou uma probabilidade de ocorrência em uma dada zona e em determinado período de um fenômeno podendo causar danos (Nações Unidas).

O evento é aquilo que ocorre de forma parcialmente imprevista, perturbando o desenrolar normal do sistema de produção, superando a capacidade da máquina de assegurar sua autoregulagem. Ele pode se manifestar em forma de panes, desvios de qualidade, falta de materiais, mudanças imprevistas na programação da fabricação, falta de energia elétrica, em suma, tudo que é chamado de acaso (ZARIFIAN, 2001). O trabalhador não fica passivo diante de um evento, mas a organização está constantemente lhe cobrando atitudes para solucionar os problemas advindos do evento. Assim, o autor aponta três procedimentos do trabalhador em relação ao evento: 1) antes do evento: expectação atenta, antecipação parcial, emprego de meios preditivos; 2) durante o evento: a intervenção ativa e pertinente, muitas vezes sob forte pressão de prazo, afinal, é preciso reparar rapidamente uma pane; 3) depois do evento: uma atitude de debruçar de forma reflexiva sobre o evento ocorrido, com frieza, para compreendê-lo, para analisar profundamente as causas e os motivos que fizeram com que o evento ocorresse com intuito de evitar novas ocorrências.

O evento é um fenômeno de perigo, de exposição a riscos, mas Zarifian (2001) o considera também uma oportunidade de aprendizagem, pois graças às análises sistemáticas das panes, os trabalhadores aprendem muito sobre o funcionamento das máquinas. Nesse contexto eles vão elaborando também o que Amalberti (1996) chama de gestão dos riscos. O evento não desejado (END) é todo evento suscetível de provocar, direta ou indiretamente, um ou mais efeitos considerados 
nefastos sobre uma pessoa, uma população, um ecossistema, um sistema material (DOS SANTOS, 2002).

b) Perigo: é a propriedade de uma substância ou de uma situação física de poder provocar danos à saúde humana e/ou ambiente (Diretriz Européia 96/82/CE conhecida como Seveso II). O perigo é a situação de um sistema no qual estão reunidos todos os fatores que podem conduzir à ocorrência de um acidente. Ele é um conceito qualitativo que exprime uma potencialidade (DOS SANTOS, 2002).

c) Indicador de perigo: é uma grandeza calculável e/ou mensurável, que permite quantificar o perigo segundo uma escala ordinal (mais ou menos perigoso). Ela está implícita ou explicitamente na base das definições e da implementação das diferentes modalidades de segurança. Em sistemas complexos, a consideração sobre perigo é resultante do produto de associações, combinações, interrelações de eventos, suscetíveis de serem ampliadas por fatores de risco, cujos efeitos são avaliáveis por cálculos de correlações que nem sempre são completas. Essa representação remete a uma concepção probalística da causalidade e invalida teoricamente a noção de risco zero.

d) Risco: é descrito em termos de probabilidade de ocorrência: "é a chance ou probabilidade que um perigo causaria um acidente, considerando a gravidade do ocorrido" (GRAYHAM, 199). Ele pode ser considerado uma medida do nível de perigo que caracteriza um evento não desejado por sua probabilidade de ocorrência, sua gravidade e aceitabilidade (MOSAR).

Riscos tecnológicos são considerados como sendo causados pelo homem podendo ser qualificados como capitais na medida em que, mesmo se a frequência for baixa, sua gravidade pode ser enorme.

e) Aceitabilidade: em relação a um risco, ela dependerá de muitos fatores. Para as Nações Unidas, trata-se do nível de perdas humanas e materiais, percebido pela comunidade ou pelas autoridades competentes, como tolerável, no âmbito das ações que visam minimizar o risco de catástrofe.

f) Dano: é a deterioração física (corporal, material, ambiental) ou moral socialmente recusada, consequência direta ou indireta, imediata ou diferida, consecutiva a um evento considerado como nefasto (MADS - MOSAR).

g) Prevenção: pode ser entendida como o ato de prestar atenção aos ambientes físicos, químicos, biológicos, sociais e econômicos com o intuito de reduzir acidentes, doenças ou morte. Ela tem a ver com educação sobre saúde e serviços de prevenção como monitoramento (DENNIS e DRAPER, 1989).

As Nações Unidas consideram a prevenção "o conjunto das ações destinadas a fornecer uma proteção permanente contra as catástrofes. Abrange as medidas práticas de proteção física relacionadas à engenharia, além das medidas legislativas que controlam a ocupação e uso do território nacional e planejamento urbano."

h) Segurança: esse conceito adquiriu um sentido mais amplo do que antes. Atualmente a segurança está, geralmente, considerada como ausência de dano à saúde (lesão ou doença) e à propriedade. Se dano é considerado o resultado de um risco, a segurança é ausência de risco. Ela depende dos conceitos de dano e risco. Estado de segurança é aquele no qual não há perigo de acontecer um acidente (ANDREÓNI, 1989).

i) Especialistas em prevenção $e$ atores de prevenção: os especialistas são aqueles encarregados das questões de segurança e prevenção nas empresas ou organizações públicas e privadas, tanto em tempo integral, quanto parcial. Ergonomistas, médicos do trabalho, inspetores do trabalho não são especialistas em prevenção, mas atores de prevenção.

A ergonomia tem um importante papel para auxiliar na compreensão dos acidentes de trabalho. A partir da noção de multicausalidade deles, entende-se que existe aí um enigma que não se conhece antecipadamente, mas que será necessário formular para agir na prevenção. Dessa forma, não pode considerar apenas uma das causas, pois reduz o campo das ações de transformação e o sucesso das ações de prevenção (GARRIGOU et al., 2007).

O acidente está inserido em uma situação complexa (ou enigma conforme Garrigou et al., 2007) que vai se construindo através da atividade desenvolvida pelo trabalhador na situação de trabalho e mobilizará: a) a pessoa e seus recursos: sua experiência, suas competências, representações da situação ou dos riscos, suas habilidades ou capacidades físicas, sua limitações e outros; b) o sistema técnico e sue ambiente: a tecnologia empregada, os materiais utilizados, as ambiências físicas e os 
riscos mecânicos, químicos, biológicos, elétricos; c) a organização do trabalho: os turnos, as normas para composição das equipes, os procedimentos de trabalho e regulamentações de segurança (GARRIGOU et al., 2007). Toda ação prevencionista, seja de engenheiros em segurança do trabalho, de médicos do trabalho ou de ergonomistas, requer uma formulação desse enigma constituído pelos aspectos supracitados.

Garrigou et al., 2007 abordam algumas noções que poderão auxiliar na reformulação do enigma:

1) Modelo de homem e articulação das diferentes dimensões que serão apresentadas a seguir:

- Dimensão biológica que considera os esforços físicos e o funcionamento biológico do corpo humano como a cronobiologia e os ritmos circadianos.

- Dimensão cognitiva que engloba os processos de aquisição, memorização, tratamento da informação, raciocínio e as decisões que são subjacentes a toda atividade humana.

- Dimensão psíquica que está relacionada à consideração do homem como sujeito-ator de uma história que contribuiu para estruturar sua personalidade. Sua vida laboral é constituinte de sua personalidade.

- Dimensão social, na qual o homem é um membro de vários grupos sociais nos quais irá se constituir um conjunto de valores e crenças que serão adotados pelos indivíduos.

É importante alertar, conforme aborda Teiger (2002), que as ações prevencionistas não devem ser focadas apenas na dimensão biológica e nos riscos de danos à integridade física, mas precisam levar em conta uma articulação bem feita dessas dimensões mencionadas. Embora seja desafiante, é possível realizar esse trabalho, desde que o profissional responsável pela ação prevencionista pratique a humildade de reconhecer que, às vezes, sua formação profissional é limitada e esteja aberto para solicitar auxílio de outros profissionais com formação diferente da sua. Essa atitude proporciona troca de experiências e complementação nas ações para promoção da saúde e segurança do trabalhador.

2) Diferentes formas de variabilidades. A gênese dos riscos em situações de trabalho se enraíza com bastante frequência em formas de variabilidades que não foram levadas em conta na concepção das situações de trabalho e na sua organização (GUÈRIN et al., 2001). Para conhecer esse enigma que está em jogo na exposição aos riscos, será necessário percorrer as diferentes formas de variabilidades.

3) Variabilidades individuais: há diferenças entre as variabilidades intra-individuais e as variabilidades interindividuais. A ergonomia busca considerar todas elas. As primeiras estão relacionadas àquelas variações do funcionamento psicofisiológico de uma mesma pessoa. Permite identificar manifestações de fadiga gerada pela atividade de trabalho, dos ciclos de sono, das flutuações da vigilância ou da atenção conforme os momentos do dia, as exigências da atividade. As variabilidades interindividuais, por sua vez, permitem enfatizar a diversidade das características entre os indivíduos que constituem uma população. Alguns exemplos são: as características antropométricas (altura, peso), sexo, idade, itinerário profissional, experiência adquirida, formação. Essas características auxiliam na explicação a respeito de representações, tomadas de decisão, comportamentos no desempenho das tarefas, compromissos aceitos.

4) Variabilidades contextuais: variações das matérias-primas, produtos fabricados, procedimentos, variações de temperatura. Esses eventos ajudam a questionar o funcionamento normal das instalações industriais e ajudam a explicar as formas de funcionamento precárias e passíveis de ocorrer acidentes.

Nas atividades de serviços, essas variabilidades podem incluir o número de clientes em uma fila de espera em um guichê dependendo do horário, a diversidade de experiência dos usuários que são atendidos, as informações a serem coletadas conforme o caso. Aumento nos momentos de espera, desentendimentos entre usuários e operadores podem regelar agressividade, degradação da qualidade do serviço e/ou das condições de trabalho.

5) Variabilidades organizacionais: tanto para a organização como para o funcionamento técnico, há formas de variabilidades que questionam o funcionamento ideal. Algumas categorias de variabilidades organizacionais são: ausências ao trabalho devido a doenças, acidente de trabalho, formação complementar (cursos para atualização), variações na composição das equipes: presença de novos contratados com variados estatutos: temporários, com duração indeterminada, horários diferentes conforme as equipes, as épocas do ano. 
Nesse contexto, a organização real precisa constantemente se recompor, se reconstruir, apoiando-se em competências profissionais individuais e coletivas que podem variar.

6) Os saber-fazer de regulação e de prudência: as interações entre as diferentes formas de variabilidade apresentadas tendem a perturbar o bom funcionamento das instalações. Em algumas circunstâncias, resultarão em disfunções significativas. A experiência do trabalhador poderá auxiliá-lo na mobilização de certo saber-fazer baseado em estratégias de regulação para antecipar a ocorrência desses eventos não desejados e, até mesmo, para recuperá-los. Às vezes essas regulações poderão ser prejudiciais para a saúde e acarretar distúrbios ou patologias a curto ou longo prazo. Elas estão no centro do enigma que a exposição a riscos profissionais representa. O saber-fazer é baseado em regulações individuais: exploração do ambiente, busca de informações formais ou informais, decisões e ações, muitas vezes sob intenso constrangimento temporal. As regulações coletivas são também mobilizadas a partir de comunicações e coordenações das ações entre os operadores. Entretanto, essas estratégias de regulação não incidem apenas no tratamento dos eventos ou dos incidentes encontrados nas situações de trabalho. Elas integram também o saber-fazer de prudência que está a elas associado.

O saber-fazer de prudência é um conjunto de atitudes, comportamentos, maneiras de operar que se direcionam para a segurança (CRU e DEJOURS, 1983). Em suma, "esses saber-fazer são aprendidos no local de trabalho observando o que os experientes fazem e, então, articulando a isso suas próprias exigências" (CRU, 1995). Eles se integram, se constituem no âmbito das regras de trabalho (GARRIGOU et al., 1998). Podem incidir em diferentes aspectos, tanto em nível individual quanto no coletivo e envolvem: a preparação das operações de risco, as maneiras de fazer durante as operações, a manutenção da atenção e da vigilância, a antecipação de imprevistos (áleas) ou variabilidades nas situações de trabalho, paradas ou truques para perceber, vivenciar e gerir o estresse ou o nervosismo, a verificação e o recuo em relação às operações realizadas, a coordenação das operações implicando diferentes atores, a vigilância em relação às dificuldades encontradas por outros operadores, como é o caso dos recém contratados, a transmissão no grupo de histórias de incidentes que sustentam a vigilância.

Todas essas questões expostas podem contribuir para descrever como se desenvolvem, através da atividade de trabalho, as condições de exposição aos riscos. No entanto, para serem operacionais, essas noções precisarão ser mobilizadas a partir do uso da análise ergonômica do trabalho que é constituída de um estudo complexo, mas que permite entre outras questões, formalizar e colocar em discussão: as diferentes formas de variabilidades e suas consequências para o trabalhador, assim como, os modos degradados e os incidentes, as situações que exigem que se corram riscos, os saber-fazer de prudência e as estratégias de economia (formas de fadiga e as reduções de vigilância), mobilizados, baseados nas representações que os operadores possuem dos riscos encontrados.

A ação ergonômica só será possível se os responsáveis por ela negociarem as condições de uma construção social de sua intervenção dando aos trabalhadores o devido lugar que é de sujeitos e atores de sua atividade que pode expô-los a riscos. É necessário também criar espaços protegidos para discussão nos quais seja possível falar de riscos cotidianos que esses trabalhadores correm, dos desvios no uso dos equipamentos, das trapaças necessárias para que a produção aconteça, entre outros (GARRIGOU et al., 2007).

Um estudo que ilustra de forma bastante completa essa questão é Diniz et. al (2005) que, ao realizarem um estudo sobre o trabalho dos motociclistas profissionais, esses autores discutem os limites das normas de segurança prescritas que desconsideram o saber desenvolvido pelos trabalhadores.

\section{Conclusão}

Apesar de todos os caminhos que muitos pesquisadores tem trilhado na tentativa de divulgação das novas abordagens para compreensão do erro e acidentes de trabalho, ainda há muitas dificuldades de acesso a publicações acerca desse novo olhar. O que foi percebido ao realizar a revisão de literatura sobre prevenção dos acidentes é que ainda, nos dias atuais, predomina a visão tradicional.

Após essa breve revisão teórica, conclui-se que o ser humano é muito complexo e seu comportamento varia, não apenas de um contexto para outro, como também dentro do próprio contexto no qual ele está inserido, por exemplo, no local de trabalho, como é o caso discutido nesse 
texto. Ele não é o mesmo todo dia, nem mesmo o dia inteiro. Seu comportamento apresenta grandes variabilidades em função de múltiplos aspectos contextuais. Essas questões dificultam as ações em prevenção de acidentes, no entanto não as inviabilizam. Assim, os profissionais que se propõem atuar nessa área devem investir em pesquisas não apenas sobre questões técnicas da segurança do trabalho, mas também nas questões referentes ao comportamento geral do ser humano. Questões sobre comprometimento, aprendizagem, motivação e outros são imprescindíveis nesse processo, conforme foi visto na visão contemporânea que aborda o tema segurança do trabalho.

Ao trabalhar com segurança do trabalhador, é muito difícil provocar mudanças em sua personalidade. É possível trabalhar uma perspectiva que vise orientações para mudanças de comportamento das pessoas. Sendo assim, cabe à empresa, preocupada com a preservação da saúde e segurança de seus colaboradores, eliminar ou, pelo menos minimizar as situações passíveis de exposição a acidentes. Isso é possível ser feito a partir de muitas atitudes como manutenção preventiva, corretiva e preditiva de equipamentos, disponibilização de equipamentos para proteção individual e coletiva, contratação de profissionais capacitados para realizar os treinamentos para orientação em relação ao desenvolvimento de novos comportamentos que sejam mais seguros que os anteriores. A avaliação realizada nesse trabalho aponta para uma necessidade de revisões na organização do trabalho, análises ergonômicas do trabalho para compreendê-lo e busca de melhorias contínuas na forma de realizá-lo. Atuar na prevenção de acidentes requer cooperação de todos os atores da empresa: projetistas das condições laborais, administradores, engenheiros e técnicos em segurança do trabalho e operadores.

No Brasil, há muito que ser feito nessa área de prevenção de acidentes de trabalho, sendo necessários mais investimentos por parte dos governos, universidades e instituições privadas não apenas para divulgação das pesquisas existentes, como também para ampliação de estudos relacionados a nova abordagem em saúde e segurança dos trabalhadores para que haja cada vez mais um foco prevencionista não somente do ponto de vista teórico, mas também nas práticas. Percebe-se ainda uma dificuldade de introdução dos pensamentos de novas abordagens sobre a segurança do trabalho. De fato, em muitos casos, quando trata-se de segurança do trabalho, as organizações adotam uma estratégia demasiadamente normativa que não contempla todas as vertentes que circundam um posto de trabalho como foi visto ser essencial a partir da abordagem contemporânea.

\section{Referências}

AMALBERTI, René. La conduite des systemes à risques. Paris: Presses Universitaires de France, 1996.

ANDREÓNI, D. Occupational safety, development and implementation of. In: Parmeggiani, L. (Ed.) Encyclopedia of Occupational Health and Safety. Genève: International Labour Office, 1989, v.2, p.1535-1538.

BLEY, J. Z. Variáveis que caracterizam o processo de ensinar comportamentos seguros no trabalho. Dissertação de mestrado. Centro de Filosofia e Ciências Humanas da UFSC. Florianópolis, 2004.

CATTINO, M. Da Chermobyl a Linate Incicenti tecnologia o errori organizzative? Roma:

CHESNAIS, M. L'identification des causes de dysfonctionnement: intérêt des techiniques d'analyses issues de la conception systémique. In: DADOY, M. et al., (Ed.). Les analyses du travail: enjeux et formes. Paris: CEREQ, 1990. p.189-192. 1990

COLETA, J. A. D. Acidentes de trabalho: fator humano, contribuições da psicologia do trabalho atividades de prevenção. São Paulo: Atlas, 1991.

CLOT, Yves. A função psicológica do trabalho. Petrópolis, Rio de Janeiro: Vozes, 2006. 
CRU, D.; DEJOURS, C. Les savoir-faire de prudence dans les métiers du bâtimente. Nouvelle contribution de la psycholigie du travail à l'analyse des accidents et de la prévention dans lê bâtiment. Les Cahiers Médico-Sociaux, v.27, p.239-247, 1983.

CRU, D. Règles de métier, langage de métier: dimension symbolique au travail et démarche participative de prévention. Paris: Laboratoire d'ergonomie physiologique et cognitive, 1995. (Memoire EPHE).

DENNIS, J.; DRAPER, P. Preventive Medicine. In: Parmeggiani, L. (Ed.) Encyclopedia of Occupational Health and Safety. Genève: International Labour Office, 1989, v.2, p.1787-1790.

DINIZ, E. P. H.; ASSUNCAO, A. A.; LIMA, F. P. A. Prevenção de acidentes: o reconhecimento das estratégias operatórias dos motociclistas profissionais como base para a negociação de acordo coletivo. Ciênc. saúde coletiva [online]. 2005, vol.10, n.4, pp. 905-916. ISSN 1413-8123.

DOS SANTOS, J. Notions de bases de la sécurité moderne et des sciences du danger. In: GUIDE d'internvention face au risque chimique. Paris: Fédération nationale des Sapeurs-Pompiers de France, 2002.

DWYER, T. A study on safety and health management at work: a multidimensional view from a developing country. In: FRICK, K., et al. Systematic occupational health and safety management. Amsterdam: Pergamon, 2000, p. 149-74.

FALZON, P. (Ed.) Ergonomia. Editora Blucher: São Paulo, 2007.

FIRENZE, R. J. The process of hazard control. Dubuque: Kendall/Hunt, 1978.

FILHO, J. M. J. Acidentes e sua prevenção. In: Revista Brasileira de Saúde Ocupacional, São Paulo: FUNDACENTRO, n.32(115): 7-18, 2007.

FLIPPO, R. F. e CAVERLEY, D. C. Teaching reading \& study strategies at the College Level, Newark, Delaware, IRA, 1991.

GARRIGOU et al. Know-how in maintenance activities and reliability in a high-risk process control plant. Applied Ergonomics, v.29, p.127-132, 1998.

GARRIGOU et al. Contribuições da ergonomia à prevenção dos riscos profissionais. In: FALZON, P. Ergonomia. São Paulo: Editora Blucher, 2007.

GRAYHAM, D. Health and safety, reference dictionary. London: Gee Publishing, 1999.

GUÉRIN, et. al.- Compreender o trabalho para transformá-lo. A prática da ergonomiaTradução: Giliane M. J. Ingratta e Marcos Maffei, São Paulo: Edgar Blucher LTDA, 2001.

HALE, A.; GENDON, A. I. Individual behaviour in the control of danger. London: Elsevier, 1987. HUTCHINS, Edwin. Comment le "cockpit" se souvient de ses vitesses. Sociologie du Travail, n.4, p.451-47,1994.

JORGENSEN, K. Concepts of accidents analyzing. In: STELLMAN, J. M., (Ed.). encyclopaedia of Occupational Health and Safety. 4 edição, Genève: International Labour Office, v.2, p.56.3-56, 1988.

KIRCHNER, J. H. Arbeitssicherheit and Ergonomic. Braunschweig, Technische Universitat; Fachgebiet Arbeitswissen-schaft, 1980.

LEPLAT, J. About implementation of safety rules. Safety Sciences, v. 2, p.198-204, 1998. 
LIMA, M. E. A. Contribuições da Clínica da Atividade para o campo da segurança no trabalho. Revista Brasileira de Saúde Ocupacional, São Paulo, 32 (115): 99-107, 2007.

LLORY, M. Acidentes industriais: o custo do silêncio. Rio de Janeiro: MultiMais Editorial, 1999.

MELIÁ, J. L. Mecición y metodos de intervención en psicologia de la seguridad y prevención de accidents. Revista de Psicologia de Trabajo y de las organizaciones, 15(2), 1999.

NORMAN, D. e ZHANG, J. Representations in Distributed cognitive Tasks. Cognitive Science, 18, 87-122, 1994.

NORMAS REGULAMENTADORAS. Disponível em http://www.mte.gov.br/legislacao.

Acesso em 08/10/2011.

PÉRILHON, P. Éléments méthodiques. Bordeaux: Éditions Préventique, 2000.

PERROW, C. Complexidade, interligação, cognição e catástrofe. ANPAD. Anais da IX Reunião Anual. Editora da Universidade Federal de santa Catarina. Florianópolis. 1985.

REASON, J. L'erreur humaine. Presses Universitaires de France, PUF, 1993. Título original: Human error. Publicado pela Cambridge University Press, 1990.

REASON, J. Managing the risks of organizational accidents, Aldershot: Ashgate, 1997.

REASON, J.; HOBBS, A. Managing maintenance error: a pratical guide. Hampshire: Ashgate, 2003.

SKIBA, R. Die Gefahrentrãger theorie. Wilhelmshaven, Hug-Co, 1973.

SOARES, E. B. Ergonomia e televendas: uma análise do erro humano. São Paulo: Blucher Acadêmico, 2011.

TEIGER C. Origines et evolutions de la formation à la prevention des risques gestes et postures em France. Relations industrielles, v.57, n.3, p.431-462. 2002.

VAUGHAN, D. The Challenger Lauch Decision. $1^{\text {a }}$ ed. Chicago. The University of Chicago press, 1996.

WOODS, D. D.: COOK, R. Nine steps to move forward from error. Cognition, Technology \& work, n.4, p.137-144, 2002.

ZARIFIAN, P. Objetivo competência: por uma nova lógica. Tradução: Helena C. Trylinki. São Paulo: Atlas, 2001. 